\title{
SEGURIDAD NACIONAL Y DROGAS ILÍCITAS: ¿UN VÍNCULO REAL O UN PROBLEMA ABIERTO?* Una reflexión a partir del caso de Colombia
}

\author{
Juan Gabriel Tokatlian**
}

El interrogante que pretende introducir este ensayo es concreto: ¿puede el ejemplo de Colombia, donde se combinan el negocio ilegal de las drogas psicoactivas, varios grupos criminales poderosos ligados a ese emporio y un claro desafío por parte de éstos para el país, ser útil para evaluar la noción de seguridad nacional y su pertinencia explicativa de este tipo de fenómeno? En este texto, intentaré una respuesta a esta pregunta con el ánimo de que contribuya a anticipar y, eventualmente prevenir, más experiencias semejantes en América Latina.

El caso de los procesadores y traficantes colombianos de drogas ilícitas ha recibido una creciente atención entre académicos, políticos, observadores, periodistas, funcionarios, tomadores de decisión y especialistas, tanto nacionales como extranjeros '. Una variedad de términos se han utilizado para identificarlos o definirlos: empresarios ilegales, carteles, narco-guerrilleros, terroristas, etc. Sin embargo, un enfoque no suficientemente contemplado es el de entender ese caso como una expresión particular de crimen organizado $^{2}$. En esa dirección se hace necesario precisar el alcance y el contenido de esta afirmación.

\footnotetext{
"Este artículo fue publicado por FASOC, año 13, n², abril - junio, 1998. Santiago de Chile.

Ph.D. en Relaciones Internacionales de The Jobns Hopkins University School of Advanced International Studies. Es Profesor Asociado de la Universidad Nacional de Colombia, donde se ha desempeñado como investigador del Instituto de Estudios Políticos y Relaciones Internacionales (IEPRI). Actualmente es Profesor Invitado en Relaciones Internacionales y Política Exterior Comparada en la Universidad de San Andrés y en FLACSO (Sede Buenos Aires), Argentina.

1. Véanse, entre varios otros, Mario ARANGO y Jorge CHILD, Narcotráfico: Imperio de la cocaína, México D.F.: Editorial Diana, 1987; Carlos G. Arrieta, Luis J. Orjuela, Eduardo Sarmiento y Juan G. TOKATLIAN, Narcotráfico en Colombia, Bogotá: Ediciones UNIANDES/ Tercer Mundo Editores, 1990; Alvaro CAMACHO, Droga y sociedad en Colombia: El poder y el estigma, Bogotá: CEREC/CIDSE, 1988; Ciro KRAUTHAUSEN y Luis F. SARMIENTO, Cocaina \& co.: Un mercado ilegal por dentro, Santafé de Bogotá: Instituto de Estudios Políticos y Relaciones Internacionales, Universidad Nacional/Tercer Mundo Editores, 1991; Carlos MEDINA GALLEGO, Autodefensa, paramilitares y narcotráfico en Colombia, Bogotá: Editorial Documentos Periodísticos, 1990; Francisco THOUMI, Economía política y narcotráfico, Santafé de Bogotá: Tercer Mundo Editores, 1994; Juan Gabriel ToKATLIAN, En el límite: La (torpe) norteamericanización de la guerra contra las drogas, Santafé de Bogotá: CEREC/Editorial
}

Norma, 1997; Sydney Jay ZABLUDOFF, “Colombian Narcotics Organizations as Business Enterprises”, en Transnational Organized Crime, N. ${ }^{\circ} 2$, Vol. 3 , Verano 1997; Alvaro Camacho Guizado, Andrés López Restrepo y Francisco E. THoumi, Las drogas: Una guerra fallida. Visiones críticas, Santafé de Bogotá: IEPRI, Universidad Nacional/Tercer Mundo Editores, 1999; Bruce M. BAGLEY, "Dateline Drug Wars. Colombia: The Wrong Strategy" en Foreign Policy, N. . 77, Invierno 1989-90; Marc Chernick, "Colombia's 'War on Drugs' vs. the United States 'War on Drugs'”, en W.O.L.A. Issues in International Drug Policy Briefing Series, N. . 3, Mayo, 1991; Suzanne Bettina Danneskiold Lassen, "Drug Trafficking and Terrorism in Colombia" en Barry RuBIN (ed.), The Politics of Counterterrorism: The Ordeal of Democratic States, Washington D.C.: Foreign Policy Institute, The Johns Hopkins University Paul H. Nitze School of Advanced International Studies, 1991; Rachel EHRENFELDT, Narco-Terrorism, New York: Basic Books, 1990; Guy GugliotTA y Jeff LeEn, Kings of Cocaine, New York: Simon and Schuster, 1989; Jonathan HARTLYN, "Drug Trafficking and Democracy in Colombia in the 1980s", en Documentos Ocasionales del Institu de Ciencies Politiques i Socials de Barcelona, 1993; Rensselaer W. LEE III, The White Labyrinth: Cocaine and Political Power, New Brunswick: Transaction Publishers, 1989; Patricia B. MCRAE, "The Illegal Narcotics Trade in Colombia: Power Contender to the State and National Security", en Conflict Quarterly, Vol. XIII, N. ${ }^{\circ}$ 2, Primavera 1993; Kevin J. RILEY, "The Implications of Colombian Drug Industry and Death Squad Political Violence for U.S. Counternarcotics Policy", en RAND Note, N-3605-USDP, 1994; William C. STARBUCK, "Narcotics Trafficking as Narco-Insurgency in Colombia and Myanmar, A Comparative Analysis", Disertación de Ph.D., University of Southern California, 1993; y John M. ROBERTSON, "Nationalism, Revolution and Narcotics Trafficking in Latin America (Colombia, Peru, Cuba)", Disertación de Ph.D., University of Virginia, 1994.

2. Sobre el crimen organizado en general véanse, entre varios otros, Howard ABADINSKY, Organized Crime, Chicago: Nelson-Hall, 1994 (4ta. Edición); Jay S. Albanese, Organized Crime in America, Cincinnati: Anderson Pub., 1989; Joseph L. AlbinI, The American Mafia: Genesis of a Legend, New York: Appleton-Century-Croft, 1971; Herbert E. Alexander y Gerald E. CAIDEN (eds.), The Politics and Economics of Organized Crime, Lexington: Lexington Books, 1985; Annelise G. ANDERSON, The Business of Organized Crime: A Cosa Nostra Family, Stanford: Hoover Institution Press, 1979; Pino ARLACCHI, Mafia Business: The Mafia Ethic and The Spirit of Capitalism, Londres: Verso, 1986; Fenton BRESLER, The Chinese Mafia, New York: Stein \& Day, 1981; Alan A. BLOCK, Perspectives on Organizing Crime: Essays in Opposition, Dordrecht: Kluwer Academic Pub., 1991; Alan A. Block y William J. Chambliss, Organizing Crime, New York: Elsevier 1981; Raimondo CATANZARO, Men of Respect: A Social History of the Sicilian Mafia, New York: Free Press, 1988; Petrus C. van DuYnE, "Organized Crime and Business Crime-Enterprises in the Netherlands", en Crime, Law and Social Change, Vol. 19, Marzo 1993; Herbert EDELHERTz (ed.), Major Issues in Organized Crime Control, Washington D.C.: U.S. Department of State, 1987; Cyrille FIJNAUT, "Organized Crime: A Comparison Between the United States of America and Western Europe", en British Journal of Criminology, Vol. 30, Verano 1990; Stepehn R. Fox, Blood and Power: Organized Crime in Twentieth-Century America, New York: W. Morrow, 1989; Stephen Handelman, "The Russian Mafiya", en Foreign Affairs, Vol. 73, Marzo-Abril 1994; Srikanta GHosh, The Indian Mafia, Nueva Delhi: 
Una evaluación de la literatura -particularmente estadounidense y europea- sobre el tema en cuestión revela un hecho inicial obvio, pero no por ello menos trascendental: en la medida en que existan bienes y servicios demandables por el público y que, sin embargo, permanezcan prohibidos o sean declarados ilegales, siempre existirán los incentivos, las oportunidades y las condiciones para que prosperen modalidades de criminalidad ${ }^{3}$. Esta demanda concreta y evidente de bienes y servicios ilícitos es la que asegura tanto la manifestación como la permanencia de un tipo de crimen; el de una criminalidad sofisticada que supera el nivel y la actuación individual y se sitúa en un marco más amplio e intrincado de organización. Así entonces, al tiempo que se mantenga y refuerce el "prohibicionismo" de las drogas psicoactivas, en esa misma forma se preservará e incrementará el poder del crimen organizado ligado a ese producto. El "prohibicionismo" mismo, por lo tanto, está en la raíz del fenómeno criminal y ello no puede pasar inadvertido ni ser tergiversado. De lo contrario, se implantarán retóricas, se construirán imágenes y se diseñarán políticas que en nada aportarán a resolver de manera seria, responsable y decisiva la problemática originaria ${ }^{4}$.

A los efectos de ubicar el ejemplo de los procesadores y traficantes colombianos de drogas ilegales, es conveniente distinguir los elementos conceptuales que ayudan a una mayor precisión y mejor caracterización del caso. En ese sentido, es posible indicar lo siguiente:

Primero, en forma independiente del grado y nivel de desarrollo económico histórico o vigente de un país, el crimen organizado florece, se amplía y hunde sus raíces con más fuerza en el capitalismo. Ello se presenta más allá del tipo de régimen político, democrático o autoritario, y de su ubicación periférica o central en el sistema internacional. El telón de fondo -la estructura- en el que se manifiesta la criminalidad organizada es el conjunto de incentivos materiales, de conflictos sociales y de prácticas políticas que hacen parte del esquema capitalista.

Segundo, el crimen organizado es un fenómeno dinámico que se circunscribe cada vez menos a la idea casi prefijada de un sólo espacio físico, de un grupo nacional y de un número reducido y limitado de productos ilícitos en control de una organización dada. La noción de criminalidad organizada no es estática aunque algunos autores (y funcionarios gubernamentales, en especial, en Estados Unidos) han pretendido circunscribirla a un momento específico, a un comportamiento único y/o a un territorio determinado. Por el contrario, asistimos a una forma empresarial delictiva que, en su evolución histórica, se ha mostrado fecunda y plural. Por ello, el alcance del crimen organizado es de carácter integral, es decir, está adquiriendo dimensiones globales (en lo geográfico), transnacionales (en lo étnico-cultural), multiformes (en las acuerdos que forja con sectores políticos y sociales) y pluriproductivas (en cuanto a la gama de productos que transa y a los distintos niveles de participación; esto es, producción, intermediación, venta, etc.).

Tercero, la criminalidad organizada se asienta en un espacio y un tiempo en los que las relaciones individuales y colectivas son facilitadoras de su maduración y poderío. Esto apunta a indicar que el crimen organizado es mucho más que un acto o una conducta, grupal aislada o unilateral, anómica o desviada. Esta modalidad de crimen se inserta en una profunda, compleja y dinámica matriz en la que la sociedad es al mismo tiempo - por diversos motivos y de modo ambivalente- víctima de sus demostraciones violentas de fuerza y beneficiaria de los bienes y servicios que provee. De igual manera, surge y se ramifica en un entorno en el que el Estado se encuentra, parcial o completamente, tácita o expresamente -según el caso concreto- en connivencia con dicha criminalidad, permitiendo de hecho que su capacidad operativa (tanto de bienes y servicios ilegales como lícitos) prospere sin control, regulación ni freno efectivos. En consecuencia, el contexto en que se desarrolla el crimen organizado es el de una cultura funcional a su desenvolvimiento.

Cuarto, la expresión crimen organizado se ha reservado exclusivamente al ámbito de los agentes no gubernamentales. Ello no significa, sin embargo, el desconocimiento de la cercana e intensa articulación entre grupos criminales con el espacio de lo estatal no sólo para su funcionamiento, sino también para su expansión. Cuando se habla de este fenómeno no se señala que tal o cual Estado responde a una

Ashish Pub., 1991; Robert J. Kelly, Ko-Lin Chin y Rufus SCHATZBERG (eds.), Handbook of Organized Crime in the United States, Westport: Greenwood Press, 1994; Peter A. LupsHA, "Individual Choice, Material Culture, and Organized Crime", en Criminology, Vol. 19, 1981; Robert F. MEIER (ed.), Major Form of Crime, Beverly HILLs: Sage Publications, 1984; Tom MIECZKOWSKI, "Drugs, Crime, and the Failure of American Organized Crime Models", en International Journal of Comparative and Applied Criminal Justice, Vol. 14, Primavera 1990; Denny F. PACE y Jimmie C. STYLES, Organized Crime: Concepts and Controls, Englewood Cliffs: Prentice-Hall, 1975; Frank PEARCE y Michael WOODIWISS (eds.), Global Crime Connections: Dynamics and Control, Toronto: University of Toronto Press, 1993; Gerald L. POSNER, Warlords of Crime: Chinese Secret Societies -The New Mafia, New York: McGraw-Hill, 1988; Peter Reuter, Disorganized Crime, Cambridge: M.I.T. Press, 1983; Kevin STENSON y David Cowell (eds.), The Politics of Crime Control, Londres: Sage Publications, 1991; y Claire STERLING, Thieves' World: The Threat of the Global Network of Organized Crime, New York: Simon and Schuster, 1994.

3. Véanse, en particular, Robert J. KELLY, "The Nature of Organized Crime and Its Operations" en Herbert Edelhertz (ed.), op. cit.; Humbert S. Nelli, "American Syndicate Crime: A Legacy of Prohibition", en David E. KYvig (ed.), Law, Alcohol, and Order: Perspectives on National Probibition, Westport: Greenwood Press, 1985; y Michael WoODIWISs, Crime, Crusades and Corruption. Probibitions in the United States, 19001987, New York: Barnes \& Noble, 1988.

4. La evolución del crimen organizado vinculado a las drogas psicoactivas es el efecto de una estrategia prohibicionista deliberada, es un síntoma y no una causa, es una consecuencia efectiva de una voluntad y decisión implícitas o explícitas y no un dato neutral, espontáneo y natural. Por ello, tanto el "prohibicionismo" como su contra-cara, la criminalidad, constituyen, en tanto expresión social, cultural, discursiva e histórica, realidades políticas insoslayables. El caso de Estados Unidos es paradigmáticamente extremo de algún modo: el "prohibicionismo" del alcohol se instauró mediante una enmienda constitucional (la Número 18 de 1919) y se abolió a través de otra enmienda (la Número 21 de 1933) de una Constitución que consta de sólo 7 artículos y 27 amendments. Apelar a ello no es tanto para comparar la prohibición del alcohol de hace varias décadas con la hipotética de las drogas psicoactivas actuales en términos de "productos similares" más o menos criminalizables. El argumento apunta, en cambio, a poner de relieve la naturaleza política que encierra el "prohibicionismo". En esa dirección y desde una perspectiva de economía política, lo crucial es observar quién gana qué, cuánto y cómo a nivel nacional e internacional. Es decir, esclarecer la distribución de ganadores y perdedores, de beneficios y costos, de ventajas y desventajas, de poder e influencia que se produce no sólo con la prohibición, sino también con el establecimiento y consolidación de formas de criminalidad organizada. Además, conviene recordar que la racionalidad que subyace a ambos se sustenta en la esperanza de una especie de represión perdurable, eficiente y salvadora: mientras el "prohibicionismo" confía en el firme logro de la abstinencia total, la lucha contra el crimen organizado se dirige a su presunta eliminación definitiva. 
definición dada de criminalidad. Por lo tanto, el sujeto de referencia para explicar el crimen organizado se identifica en la sociedad, pero refleja asimismo una determinada relación sociedad-Estado.

Quinto, una constante detectable en las diversas aproximaciones teóricas y en las distintas experiencias empíricas evaluadas es la búsqueda de poder político y económico por parte del crimen organizado. A nivel local o global, a partir de diferentes bienes o servicios ilegales, de modo más o menos violento y con mayores o menores atributos recursivos, la criminalidad organizada pretende garantizar e incrementar sus ganancias, su influencia y su seguridad. De allí que el objeto último del crimen organizado es asegurar y proyectar su dominación social.

Sexto, si bien la violencia y la amenaza del uso de la fuerza, así como el soborno y la corrupción son elementos distintivos del crimen organizado, la fortaleza represiva no es el único mecanismo o instrumento que lo caracteriza. La criminalidad organizada tiene, en la mayoría de los casos, la necesidad, oportunidad y capacidad para combinar con eficacia la coerción y el consenso. Su vigencia y proliferación no radican sólo en su ejercicio del temor, sino también en su aceptación o reconocimiento por parte de distintos segmentos de la población. Esto evidencia la posibilidad y el interés de la criminalidad de convertirse en un actor social con potencialidad hegemónica. Para ello, además de la fuerza requiere de la persuasión. Esto hace que los medios que utiliza el crimen organizado para afirmarse y extenderse sean, preferente pero no exclusivamente, violentos.

Séptimo, la criminalidad organizada no parece responder a un patrón rígido de conformación y comportamiento grupal. El crimen organizado se apoya en coaliciones, asociaciones y conexiones de distinta índole, pero generalmente no constituye un tipo de burocracia, corporación, cartel o conglomerado homogéneo, consistente y monolítico. Los lazos internos, familiares, regionales, étnicos, nacionales y hasta religiosos son esenciales y se yuxtaponen con formas de agrupación y alianza múltiples. Pueden presentarse casos más cerrados o abiertos de aglutinación de vínculos criminales. De hecho, una importante variedad de ejemplos históricos muestra una tendencia hacia diversos esquemas híbridos de evolución, agrupamiento y acción. Ahora bien, en ellos parece predominar un hilo conductor relativamente semejante: una visión sencilla, práctica, utilitaria de la realidad y de cómo aprovecharla para mejorar y elevar su inserción política, su legitimidad social y su gravitación económica. La ideología poco o nada cuenta. Así, el ethos del crimen organizado es profundamente pragmático.

Octavo, es posible discernir una disposición similar entre las múltiples manifestaciones de criminalidad organizada. Una suerte de espíritu común aglutina las muy diversas formas de crimen organizado: un apego al statu quo, a la preservación de sus privilegios, a la defensa de ciertos valores funcionales a sus intereses, al mantenimiento de un orden básico determinado. Más que pretender una transformación estructural o sistémica, la criminalidad organizada, a pesar de utilizar medios violentos para alcanzar sus fines, tiende a perpetuar un esquema socio-político dado. Podría decirse que detrás de un supuesto desafío al régimen o a las institu- ciones imperantes, el crimen organizado busca ser eventualmente cooptado. De allí que su orientación sea conservacionista en el sentido de preservar y perpetuar, más que superar radical o gradualmente, lo establecido.

Resumiendo, el crimen organizado surge de una prohibición concreta, se desarrolla en una estructura capitalista, alcanza crecientemente una dimensión integral, opera un contexto cultural que es funcional a su desenvolvimiento, tiene como sujeto de referencia a un actor social inmerso en una particular dinámica sociedad-Estado y cuyo objeto prioritario es asegurar y proyectar su dominación, actuando con medios preferente pero no exclusivamente violentos, apoyado en un ethos pragmático y portador de una orientación conservacionista.

El caso de los procesadores y traficantes colombianos de drogas psicoactivas, en tanto fenómeno en el que se expresa con nitidez lo señalado, constituye un ejemplo de criminalidad organizada. La prohibición del consumo de estupefacientes y sustancias psicotrópicas ha sido el motor que ha alimentado la configuración del crimen organizado en Colombia. Los procesadores y traficantes nacionales se han insertado en una estructura capitalista tardía y dependiente, caracterizada en las últimas cuatro décadas por un crecimiento económico acelerado, dinámico y rapaz que generó un proceso vertiginoso y contradictorio de modernización; modernización inconclusa dado que no fue acompañada por un desarrollo paralelo y efectivo de los elementos básicos de la modernidad. Con el tiempo, los procesadores y traficantes colombianos de drogas ilegales han ido mostrando un alcance cada vez más integral, multiplicando la producción, comercialización y distribución de productos ilícitos en diversos mercados y ampliando los contactos y compromisos con otros grupos extranjeros de criminalidad organizada. La diversidad social de sus integrantes -en cuanto grupos provenientes de situaciones históricas, geográficas y regionales distintas aunque bajo una matriz sociedadEstado similar identificada por un débil desarrollo estatalno ha impedido el hecho sobresaliente de que el objeto genérico del crimen organizado colombiano ligado a las drogas psicoactivas sea idéntico: incrementar su poder económico, elevar su influencia política y legitimar su presencia social. Esta criminalidad se ha asentado en el país gracias a un entorno cultural cuyos valores y prácticas individuales, sociales, políticas y jurídicas han facilitado al crimen organizado nacional su expansión ascendente y su potencial consolidación. A su vez, éste ha usado la violencia de modo preferencial, aunque no único, para alcanzar sus propósitos y asegurar sus intereses. En el ejemplo colombiano, de modo concomitante, el ethos pragmático ha sido una nota identificatoria del comportamiento de los procesadores y traficantes de drogas ilícitas; estableciendo acuerdos, pactos y transacciones prácticas, transitorias, reiteradas, decisivas -según el caso- con una vasta gama de agentes gubernamentales y no estatales, armados y desarmados, legales e ilegales, sistémicos y anti-sistémicos. Finalmente, la orientación conservacionista del crimen organizado nacional ha sido evidente, incluso en las coyunturas y circunstancias en que ha utilizado la violencia de manera más brutal: los procesadores y traficantes de drogas ilícitas más que derro- 
car al sistema imperante, quieren ser parte de él; lo que no significa, sin embargo, que necesariamente deseen un régimen democrático.

Lo que distingue a este caso de otros ejemplos es que la narco-criminalidad organizada colombiana se desplegó y prosperó en lo que podría denominarse, a manera de metáfora, como el período (desde finales de los setenta en adelante) del segundo cuasi-colapso parcial del Estado nacionals. De allí que llegara a ser percibida como una modalidad de criminalidad organizada proto-estatal. Ello, junto al hecho de que el lucrativo negocio ilícito de las drogas psicoactivas se convirtió durante los ochenta para Washington en una amenaza crítica a la seguridad nacional estadounidense, contribuyen a explicar porqué, a nivel interno en Colombia, se alcanzó a definir a este tipo de crimen organizado como un fenómeno de seguridad nacional ${ }^{6}$.

Según Oquist, tanto la "simultánea evolución de numerosos conflictos" como un Estado debilitado y excluyente convergieron en la Violencia. En ese contexto, las "diferentes articulaciones concretas" del colapso parcial estatal que precipitaron dicha Violencia se manifestaron en: “1) la quiebra de las instituciones políticas establecidas; 2) la pérdida de la legitimidad del Estado para una porción considerable de la población; 3) las contradicciones dentro del aparato armado del Estado; y 4) la ausencia física del Estado en algunas zonas del país" '. En el período más reciente, desde mediados de los setenta hasta los noventa, salvo por el tercer factor, que no se exacerbó pero que múltiples expresiones sociales y políticas de conflicto violento se encargaron de agrietar con el consecuente desprestigio de los cuerpos de seguridad del Estado, los otros indicadores re-emergieron con fuerza y se profundizaron a tal punto que se necesitó de una Asamblea Constituyente y de una nueva Constitución en 1991 para evitar una catástrofe institucional a principios de la última década. Y a ello se debe sumar, como un dato crucial novedoso y más próximo, la verdadera inoperancia de la justicia y la rampante impunidad que ha vivido el país.

Por eso, la multiplicación, entrecruzamiento y retroalimentación de viejas y nuevas disputas, junto a la recurrencia de un Estado frágil y fracturado, en un contexto de descrédito del régimen político, aceleraron la tremenda degradación de los conflictos sociales y la descomposición de los derechos humanos en Colombia; lo cual contribuyó a generar un espacio y un entorno propicios para el encumbramiento de una narco-criminalidad proto-estatal ${ }^{8}$. Así entonces, y aún luego de la nueva Carta de 1991, la debilidad del poder estatal, la baja credibilidad institucional y la dificultad de relegitimar el sistema, han empujado al régimen político hacia un límite cercano a una crisis de gobernabilidad.

En esa dirección, Schmitter ha identificado cuatro indicadores de ingobernabilidad que son aplicables a Colombia $^{9}$. Primero, la indisciplina; la cual se manifiesta cuando los ciudadanos intentan "influir en las decisiones públicas por métodos violentos, ilegales o anómalos”. En el país, no sólo los actores paraestatales -criminalidad organizada, guerrilla, paramilitares-, sino también los agentes institucionales oficiales y privados recurren cada vez más a instrumentos de fuerza y a mecanismos ilícitos para incidir sobre las políticas públicas.
Segundo, la inestabilidad; la cual se produce cuando las elites fracasan en su intención por "conservar sus posiciones de dominación”. En Colombia, las elites han sido incapaces en los últimos lustros de forjar un proyecto unificador o consensual para superar los graves problemas de violencia del país. Tercero, la ineficiencia; la cual significa la creciente incapacidad de una administración de lograr metas deseadas, asegurando el "acatamiento de ellas por medio de medidas de coordinación obligatorias o de decisiones emanadas de la autoridad del Estado". La progresiva debilidad estatal ha reducido de manera notoria el margen de acción del ejecutivo, la aceptación ciudadana de las medidas oficiales, las posibilidades de concertación social y la capacidad de alcanzar propósitos nacionales unívocos. Y cuarto, la ilegalidad; la cual se expresa cuando los poseedores de poder e influencia persiguen "evadir restricciones legales y constitucionales en búsqueda de ventajas e incluso de su propia supervivencia”. En años recientes -y en especial durante el gobierno del Presidente Ernesto Samper (1994-1998) desde el Estado y desde el ámbito no gubernamental, los agentes más poderosos han agudizado un comportamiento orientado a la maximización de beneficios particulares y al aseguramiento de su propia sobrevivencia en desmedro de los intereses nacionales en su conjunto.

Ahora bien, dada la caracterización realizada de los procesadores y traficantes de drogas psicoactivas en el país, resulta fundamental plantear el siguiente interrogante: ¿constituye el narco-crimen organizado colombiano un fenómeno de seguridad nacional? La pregunta es ineludible si se

5. La noción de derrumbe parcial del Estado durante el período de la violencia liberal-conservadora (1948-1958) fue acuñada por Paul OQUIST, Violencia, conflicto y politica en Colombia, Bogotá: Biblioteca Banco Popular, 1978.

6. Sobre el tema véanse, entre otros, Bruce M. BAGLEY, “The New Hundred Years War? U.S. National Security and the War on Drugs in Latin America", Journal of Interamerican Studies and World Affairs, Vol. 30, N." 1, Primavera 1988; Bruce M. Bagley y Juan G. TOKATlian, "Dope and Dogma: Explaining the Failure of U.S.-Latin American Drug Policies”, en Jonathan Hartlyn, Lars Schoultz y Augusto VARAS (eds.), The United States and Latin America in the 1990s: Beyond the Cold War, Chapel Hill: University of North Carolina Press, 1992; y Juan G. TOKATLIAN, "National Security and Drugs: Their Impact on Colombian-U.S. Relations”, en Journal of Interamerican Studies and World Affairs, Vol. 30, N. ${ }^{\circ} 1$, Primavera 1988.

7. Paul OQUIST, op. cit., p. 255.

8. En un sugestivo ensayo sobre la configuración de los Estados en Europa, Charles Tilly utiliza la metáfora del crimen organizado, sus objetivos y su comportamiento para explicar cómo la evolución y el desarrollo estatal se asemejan a ese fenómeno. Para él, "if protection rackets represent organized crime at its smoothest, then war making and state making -quintessential protection rackets with the advantage of legitimacy- qualify as our examples of organized crime...I want to urge the value of that analogy...war making, extraction, and capital accumulation interacted to shape European state making...the builders of national power all played a mixed strategy: eliminating, subjugating, dividing, conquering, cajoling, buying as the occasions presented themselves". Si invertimos la imagen presentada por Tilly, el narco-crimen organizado colombiano ha ido evolucionando hacia una forma proto-estatal no tanto por un presunto crecimiento de su legitimidad o por una abrumadora acceptacción ciudadana de su proyecto socio-político, sino por la debilidad de la legitimidad institucional y por la existencia de un capitalismo voraz y concentrador del ingreso, poco sensible a la equidad y al bienestar colectivo. Véase, Charles TILLY, "War Making and State Making as Organized Crime", en Peter B. EVANS, Dietrich RuESCHEMEYER y Theda SKOCPOL (eds.), Bringing the State Back In, Cambridge: Cambridge University Press, 1985, pp. 171-175.

9. El planteamiento de Philippe C. Schmitter aparece en Manuel AlCÁntara, "De la gobernabilidad", en América Latina Hoy, Segunda Época, N. ${ }^{\circ} 8,1994$. 
busca una relativa precisión y claridad respecto a la criminalidad organizada en Colombia, su evolución histórica y su tratamiento por parte del Estado y la sociedad en los últimos años.

En ese sentido, un balance analítico en torno a la noción de seguridad nacional aporta elementos importantes que ayudan no tanto a precisar y resolver de modo categórico el significado y alcance de este término, sino a problematizar su aproximación y entendimiento ${ }^{10}$. Así, entonces, es posible afirmar lo siguiente:

En primer lugar, la idea de seguridad nacional encierra necesariamente disputa, controversia, polémica. La seguridad nacional es lo que se denomina un "concepto básicamente controvertible" ". Es difícil hallar un consenso en la manera de abordarlo, identificarlo y definirlo. No prevalece un enfoque homogéneo, totalizador y comprehensivo que dilucide una suerte de esencia objetiva en la determinación de lo que es o debe ser la seguridad nacional. Por ejemplo, ¿cuál es el sujeto de referencia de la seguridad nacional? ¿el individuo, la nación, el gobierno, el régimen, el Estado? ¿cuál es el nivel de análisis de la seguridad? ¿el local, el regional, el internacional? Ahora bien, el reconocimiento de la naturaleza controversial de este término no sólo debería conducir a ampliar y profundizar el debate acerca del mismo, sino también a diversificar e incorporar voces distintas sobre este asunto. De hecho, las voces que predominan en ese debate siguen siendo las de las naciones más industrializadas.

En segundo lugar, la idea de seguridad nacional remite al terreno de la percepción y, consecuentemente, al de la interpretación. La referencia casi obligada al escrito de Arnold Wolfers sobre el tema es ilustrativa y elocuente. Su famoso artículo de los cincuenta se titulaba "National Security as an Ambiguous Symbol" "2. Con mucha lucidez, el autor no hablaba siquiera de la seguridad como un concepto o término o hecho ambiguo, sino como un símbolo cargado de ambigüedad. De lo anterior se puede concluir que estamos frente a una noción tentativa más que definitiva, determinada valorativamente y no supuestamente neutra y mucho más compleja de lo que a veces se afirma de manera reduccionista y sencilla. El quién defina la seguridad, el cómo y el para qué resultan clave y no son aspectos eludibles al momento de evaluar el diseño y la praxis de las políticas concretas en ese campo. La consideración de la seguridad como un objetivo relativo más que como un recurso absoluto es otro elemento a tener en cuenta.

En tercer lugar, durante el período histórico de la Guerra Fría la idea de seguridad nacional adquirió un sesgo especial y recibió una lectura particular entre la gran mayoría de tomadores de decisión, especialistas y observadores. En términos de las relaciones internacionales, se alimentó del realismo y del neorealismo, ubicando en un lugar privilegiado la seguridad del Estado. En términos ideológicos de las representaciones y prácticas de los países capitalistas más industrializados, se orientó a asegurar la identidad estatal mediante la identificación de amenazas externas de peligro, cuyo epítome principal, aunque no único, era el comunismo. En términos organizacionales y de estrategia, si bien se contemplaba un abanico de frentes y modos de responder a los desafíos externos -a través de políticas diplomáticas, mili- tares y económicas- la tendencia observada fue fortalecer la dimensión o el sector armado/militar/bélico para proteger la (in)seguridad estatal. Esta triple impronta histórica de la idea de seguridad nacional no parece haber sufrido aún cambios a pesar del derrumbe de la Unión Soviética y del colapso del comunismo. Lo que tiende a predominar en la actualidad es una especie de "securitización" de un gran número de problemas, sean ellos la depredación del medio ambiente, las migraciones incontroladas, la demanda y oferta de drogas ilícitas, la pérdida de competitividad comercial y tecnológica, los conflictos étnicos, nacionales y religiosos, etc. Además, estos problemas, en general, son vistos todavía desde la lógica estatal, a manera de asechanzas polimorfas y con una tentación a resolverlos por la vía del uso expeditivo de una mayor fuerza. La agenda de seguridad se amplió pero los parámetros de comprensión y tratamiento inter-estatal aún están signados por la racionalidad de la Guerra Fría: la coerción, la amenaza, la presión y la retaliación -como

10. Sobre el tema de la seguridad nacional véanse, entre varios, Edward E. AzAR y Chung-in MOON (eds.), National Security in the Third World, Aldershot: Edward Elgar Pub., 1988; Mohammed AyOOB, "The Security Problematic of the Third World", en World Politics, Vol. 43, N." 2, 1991; Bruce M. Bagley y Sergio Aguayo Quezada (eds.), Mexico: In Search of Security, New Brunswick: Transaction Publishers, 1993; Barry BuZAN, People, States and Fear: An Agenda For International Security Studies in the Post-Cold War Era, Boulder: Lynne Rienner Pub., 1991 (2da. Edición); David CAmpbell, Writing Security: United States Foreign Policy and the Politics of Identity, Minneapolis: University of Minnesota Press, 1992; Brian L. JoB (ed.), The Insecurity Dilemma: National Security of Third World States, Boulder: Lynne Rienner Pub., 1992; Daniel J. KaUfMaN, Jeffrey S. MCKITRICK y Thomas J. LENEY (eds.), U.S. National Security: A Framework for Analysis, Lexington: Lexington Books, 1985; Francisco LEAL y Juan G. TOKATLIAN (comps.), Orden mundial y seguridad: Nuevos desafios para Colombia y América Latina, Santafé de Bogotá. Instituto de Estudios Políticos y Relaciones Internacionales, Universidad Nacional/Sociedad Internacional para el Desarrollo, Capítulo Colombia/Tercer Mundo Editores, 1994; Arthur MACY COX, The Myths of National Security: The Peril of Secret Government, Boston: Beacon Press, 1975; Robert MANDEL, The Changing Face of National Security: A Conceptual Analysis, Westport: Greenwood Press, 1994; Peter MANGOLD, National Security and International Relations, Londres: Routledge, 1990; Joseph J. Romm, Defining National Security: The Nonmilitary Aspects, New York: Council on Foreign Relations Press, 1993; Sam S. Sarkesian, U.S. National Security: Policymakers, Processes, and Politics, Boulder. Lynne Rienner Pub., 1994 (2da. Edición); Lars ScHOULTz, National Security and United States Policy toward Latin America, Princeton: Princeton University Press, 1987; Lars SCHOULTZ, William C. SMITH y Augusto VARAS (eds.), Security, Democracy, and Development in U.S.-Latin American Relations, New Brunswick: Transaction Pub., 1994; Ronnie D. LIPSCHUTZ (ed.), On Security, New York: Columbia University Press, 1995; Michael J. SHAPIRO, "Stretegic Discourse/Discursive Strategy: The Representation of 'Security Policy' in the Video Age”, en International Studies Quarterly, Vol 34, N. ${ }^{\circ}$ 3, Septiembre 1990; Caroline ThOMAS, In Search of Security: The Thirld World in International Relations, Boulder: Lynne Rienner Pub., 1987; Augusto Varas (ed.), Hemispheric Security and U.S. Policy in Latin America, Boulder: Westview Press, 1989; VARIOS AUTORES, Paz y seguridad en América Latina y el Caribe en los noventa, Lima: Centro Regional de las Naciones Unidas para la Paz, el Desarme y el Desarrollo en América Latina y el Caribe, 1992; R.B.J. WALKER, "Security, Sovereignty and the Challenge of World Politics”, en Alternatives, Vol. 15, N. 1 1, Invierno 1991; y Thomas G. WEISS y Meryl A. Kessler (eds.), Third World Security in the Post-Cold War Era, Boulder: Lynne Rienner Pub., 1991.

11. Esta expresión la utiliza Barry Buzan con base en la noción de W. B. GALliE. Véanse, Barry BUZAN, op.cit., p. 7 y W.B. GALliE, "Essentially Contested Concepts", in Max BLACK (ed.), The Importance of Language, Englewood Cliffs: Prentice-Hall, 1962.

12. Véase, Arnold WOLFERS, Discord and Collaboration: Essays on International Politics, Baltimore: The Johns Hopkins University, 1962. El ensayo sobre "National Security as an Ambiguous Symbol" incluido en ese texto se publicó originalmente en la revista Political Science Quarterly, Vol. LXVII, N. ${ }^{\circ}$ 4, Diciembre 1952. 
parte de la creencia en el instrumento militar como alternativa de solución de las dificultades generadas por aquellos fenómenos- aún están vigentes e incluso pueden exacerbarse en la medida que crezcan las fricciones y tensiones en torno a los mismos.

En cuarto lugar, la idea de seguridad nacional parece contener dilemas inexorables desde el ángulo de los Estados. En el caso de los países centrales del sistema, se hace énfasis en el "dilema de seguridad"; esto es, la búsqueda de la seguridad individual irrestricta produce inseguridad en otras contra-partes externas y ello conduce a que los diferentes actores operen procurando garantizar su propia seguridad con lo que se confirma una relativa inseguridad general ${ }^{13}$. En el caso de los países periféricos del sistema, se hace mención al "dilema de inseguridad"; esto es, la búsqueda de la seguridad estatal produce inseguridad en diversos actores sociales internos pues el Estado en cuestión no es suficientemente legítimo, lo que reduce la capacidad del Estado para proveer orden y paz doméstica y eleva la inseguridad general de una nación ante la potencial influencia y eventual acción de contra-partes del exterior ${ }^{14}$. La diferencia fundamental entre ambos dilemas es que el primero da por supuesta, firme e inmodificable la legitimidad de los actores principales -los Estados- envueltos, mientras el segundo parte de una casi permanente, indudable y caótica ilegitimidad de los actores principales -los Estados- comprometidos.

En quinto lugar, la idea de seguridad nacional es la expresión de un discurso determinado. Este discurso, invocado tanto en el Norte como en el Sur, en el ex-Este y el Oeste, es de naturaleza conservadora: busca preservar el estado de cosas existentes dando por sentado que ello es viable, deseable y necesario. Es, además, un discurso que pretende otorgar certezas: intenta precisar, medir y predecir eficazmente las amenazas, las vulnerabilidades, el tipo, grado, origen, dimensión, foco y alcance del peligro y las estrategias más convenientes y efectivas para superarlo y así evitar el conjunto de riesgos, sorpresas y dificultades vitales que ponen en entredicho valores preciados para una comunidad dada. Asimismo, conjuga un discurso orientado a fijar imágenes: esclarece u oscurece, según el caso, el perfil del adversario, del contrincante, del enemigo y su eventual futuro comportamiento, y mediante ello deposita en unos pocos ilustrados la capacidad de identificarlos y actuar en consecuencia.

En sexto lugar, la idea de seguridad nacional en el contexto hemisférico está asociada a una doctrina. La denominada Doctrina de Seguridad Nacional, surgida al calor de la Guerra Fría y estimulada fuertemente por Estados Unidos, significó "el mayor esfuerzo latinoamericano para militarizar el concepto de seguridad" ${ }^{15}$. El gran enemigo externo -el comunismo- pasó a mimetizarse a nivel doméstico y, con ello, el papel de las fuerzas armadas adquirió preponderancia, ya que la corporación militar se auto-identificó ideológica y prácticamente como la única institución capaz de salvaguardar los valores nacionales, garantizar la estabilidad política, robustecer el desarrollo social y facilitar el progreso económico de un país. Este sello doctrinario dependiente y distintivo de la seguridad nacional en América Latina se encuentra en un tibio proceso de redefinición y transformación y aún gravita de modo sobresaliente en diversos casos continentales en los que se expresan movimientos insurgentes $\mathrm{y}$ temblores institucionales que no permiten afianzar formas democráticas de convivencia y gobernabilidad. A su vez, al creciente descrédito de la doctrina en la región, se suma una natural desconfianza social ante las invocaciones a la seguridad nacional, pues se entiende que ésta le puede, eventualmente, brindar protección y defensa a las clases gobernantes pero inseguridad e incertidumbre a los ciudadanos.

A partir de esta rápida revisión, es notorio el hecho de que todavía el lente primordial del Estado es a través del cual se continua mirando y proyectando la idea de seguridad nacional. Con más o menos variaciones, matices y niveles de complejidad, las perspectivas que dominan la literatura sobre el tema se inician en el Estado o regresan a él para comprender los méritos o las deficiencias de la noción de seguridad nacional. La seguridad nacional que prima, entonces, es la del Estado. Este es un dato elocuente más allá de los intentos por superar los innumerables nudos gordianos generados por el tema en cuestión.

Luego de la caracterización de la criminalidad efectuada, ahora resulta pertinente ligarla a la reflexión en torno a la seguridad. Por una parte, los vicios o placeres -como se los desee definir-individuales o grupales vinculados a diversos productos psicoactivos naturales y/o sintéticos no constituyen necesariamente problemas de seguridad de tipo social o comunitario, ni son problemas de seguridad para un régimen o un Estado. Sin duda, generan enormes dificultades emocionales, psicológicas, morales, de salud entre la ciudadanía. Es claro, además, que deberían ser fenómenos de atención fundamental de las políticas públicas. Sin embargo, es el prohibicionismo de un recurso determinado el que motiva el escalamiento en la identificación de un bien o servicio ilegal como un asunto que amerita un tratamiento más vehemente, decisivo y contundente. Inicialmente y antes de su prohibición expresa, las drogas psicoactivas -su consumo, distribución, tráfico, procesamiento y cultivo o producción- no constituyen per se e ipso facto una cuestión de seguridad nacional ${ }^{16}$.

Por otra parte, la consecuencia de una prohibición, manifestada a través del surgimiento del crimen organizado, desnuda, exacerba y profundiza las tensiones y contradicciones sociales, políticas e internacionales entre sociedades y

13. Véase, en particular, John H. HERz, "Idealist Internationalism and the Security Dilemma”, en World Politics, Vol. 2, 1950.

14. Véase, en particular, Brian L. JOB, "The Insecurity Dilemma: National, Regime, and State Securities in the Third World", en Brian L. Job, op.cit.

15. Francisco LEAL, El oficio de la guerra: La seguridad nacional en Colombia, Santafé de Bogotá: Instituto de Estudios Políticos y Relaciones Internacionales, Universidad Nacional/Tercer Mundo Editores, 1994, p. 15.

16. Una detallada evaluación de las probables relaciones construibles entre seguridad y drogas ilícitas se encuentra en el ensayo de Jorge CHABAT, "Seguridad nacional y narcotráfico: Vínculos reales e imaginarios", en Política y Gobierno, Vol. 1, N. ${ }^{\circ} 1$, Enero-Junio 1994. Un trabajo adicional importante respecto a este tema se encuentra en Guadalupe GONZÁLEZ G., "El narcotráfico como un problema de seguridad nacional", en Documento de Trabajo Comisión Sudamericana de Paz, N. 2,1990 . Sobre las implicaciones que se desprenden del asunto de las drogas psicoactivas visto como un tópico de seguridad nacional en Washington y Bogotá véase, Max G. MANWARING, "National Security Implications of Drug Trafficking for the USA and Colombia”, en Small Wars E Insurgencies, Vol. 5, N.' 3, Invierno 1994 
estados. La misma sociedad que sufre las consecuencias negativas de la criminalidad organizada obtiene ventajas y beneficios de su establecimiento y reproducción. El mismo Estado, que en mayor o menor grado coexiste y convive con el crimen organizado, puede decidir enfrentarlo con mayor o menor fuerza, parcial o totalmente, de modo regular o en ciertas ocasiones. La decisión de transformar a la criminalidad organizada en un asunto de seguridad nacional es el resultado de una voluntad política, de una construcción discursiva y de una praxis cultural que la hace posible y necesaria; posibilidad y necesidad no abstractas sino funcionales para algunos grupos e intereses internos y externos.

A la ambivalencia (conceptual y práctica) respecto a la criminalidad organizada, se le agrega la ambigüedad (teórica y empírica) de la idea de seguridad nacional. De allí, que la determinación de convertir la criminalidad organizada en un problema de seguridad nacional para un Estado no puede ocultar una suerte de esquizofrenia. En efecto, definir con tanta precisión y certeza una relación tan compleja y contradictoria es algo imprudente, extraño e incluso peligroso.

La particularidad del narco-crimen organizado en el contexto de un país periférico como Colombia caracterizado por un profundo deterioro de los derechos humanos, por múltiples formas de violencia y por un Estado relativamente precario, es que su tratamiento como cuestión de seguridad nacional casi que preanuncia un incremento de la violencia ligada a ese fenómeno y pocas probabilidades de resolver satisfactoriamente el problema original de la demanda y oferta de drogas psicoactivas. Hay algo así como una dolorosa perversidad pre-anunciada en la determinación de "securitizar" el tema de la criminalidad organizada en el país.

En un ensayo que resume el estado de los estudios sobre seguridad y sugiere nuevas líneas de investigación, Helga Haftendorn afirma que "las percepciones de amenaza y los conceptos de seguridad se formulan como resultado de un proceso político y social al interior de los Estados y son, en grados diferentes, sensibles a las interacciones transnacionales" ${ }^{17}$. Esta interesante aseveración se concentra en el nivel estatal, dejando por fuera a la sociedad o asumiendo una correspondencia total de intereses, necesidades y objetivos entre la sociedad y el Estado. Reconociendo esa limitante o falta de claridad, la aserción sirve de guía para comprender lo que se podría denominar el "dilema estratégico" colombiano. Ese dilema se expresa de la siguiente manera:

A) En un momento histórico dado, la elite civil de un Estado débil define que la amenaza del narco-crimen organizado colombiano se constituye en un problema de seguridad nacional ${ }^{18}$. Dicha determinación se realiza en un contexto geopolítico donde el hegemón continental incuestionable es Estados Unidos; referente principal de Colombia en todos los terrenos (diplomático, militar, comercial, financiero, tecnológico, etc.) y país donde se produce el mayor consumo del conjunto de drogas psicoactivas. Esa decisión se enfrenta, asimismo, a tres realidades internas que la hacen inoperante en la práctica.

1. El estamento militar operando bajo la lógica de la doctrina de seguridad nacional -de inspiración estadounidense- en la que el enemigo principal es la insurgencia armada de izquierda, como brazo del comunismo internacional, no identifica a la narco-criminalidad organizada como un asunto prioritario de seguridad nacional a pesar del enorme grado de violencia social e inestabilidad política que ella genera.

2. La capacidad corruptiva de la narco-criminalidad organizada de importantes segmentos civiles, policiales y militares del Estado hace difícil, sino imposible el combate comprehensivo y efectivo de ese fenómeno de acuerdo al modo e intensidad que se espera sea confrontado un problema de seguridad nacional.

3. La actitud oscilante, incongruente, tolerante, mutable y dispar de la sociedad ante los costos y los beneficios generados por la narco-criminalidad y el fuerte disenso y la profunda desconfianza ante la definición estatal de dicho fenómeno como asunto de seguridad nacional, no le otorgan suficiente respaldo, credibilidad y legitimidad a la política pública contra el crimen organizado vinculado a las drogas psicoactivas.

B) Independiente de la definición estatal de narco-criminalidad organizada como cuestión de seguridad nacional, y de la operatividad/viabilidad de esa definición, el hecho de que el Estado, en Estados Unidos, haya determinado que la entrada de drogas ilegales a su territorio constituye un problema de su seguridad nacional, coloca una serie de presiones y restricciones al Estado colombiano quien no puede evitar "securitizar" el tratamiento del fenómeno a riesgo de que el país mismo, más que el negocio ilícito en sí, se convierta en una amenaza para la seguridad estadounidense y en una excusa para acciones de fuerza.

Por lo tanto, el "dilema estratégico" colombiano conduce al país a una encrucijada trágica insuperable dada la racionalidad vigente; racionalidad que refuerza el "prohibicionismo" y con ello, la espiral de violencia delictiva, corrupción rampante y rentabilidad espectacular. Eludir la confrontación total de la narco-criminalidad organizada debilita internacionalmente a Colombia. Asumir el enfrentamiento absoluto del narco-crimen organizado debilita nacionalmente al gobierno de turno. La pasividad frente al fenómeno de las drogas psicoactivas debilita externa e internamente al país.

Esta situación que hoy identifica a Colombia bien puede repetirse en uno o más países latinoamericanos. Y para ello, la región no parece provista de respuestas políticas y sociales ni de estrategias integrales y concertadas; todo lo cual podría reforzar la idea de que mediante las "securitización" del fenómeno de las drogas se obtendrá la panacea de su superación rápida, contundente, definitiva.

17. Helga HafTENDORn, "The Security Puzzle. Theory-Building and Discipline-Building in International Security", en International Studies Quarterly, Vol. 35, N. ${ }^{\circ} 1$, Marzo 1991, p. 13.

18. La concepción de debilidad estatal que se utiliza en la presentación del "dilema estratégico" se apoya en el enfoque de Barry Buzan sobre "Estado débil" en el ámbito de la seguridad. Para él, "weak states... will refer to the degree of socio-political cohesion... weak states either do not have, or have failed to create, a domestic political and societal consensus of sufficient strength to eliminate the large-scale use of force as a major and continuing element in the domestic political life of the nation". Véase Barry Buzan, op. cit., pp. 97 y 99. 


\section{RESUMEN}

Tokatlian intenta establecer la relación entre la existencia del negocio ilegal de las drogas psicoactivas de varios grupos criminales poderosos ligados a ese emporio y las consecuencias que tiene para la concepción de la seguridad nacional en el caso colombiano. Así, plantea el "dilema estratégico" colombiano en una doble dimensión: un enfrentamiento total contra el narco-crimen organizado debilita nacionalmente al gobierno de turno, pero el eludir la confrontación de la narco- criminalidad organizada debilita a Colombia internacionalmente. drogas.

Palabras clave: Colombia, drogas psicoactivas, criminalidad organizada, seguridad nacional, negocio ilegal de

\section{ABSTRACT}

Tokatlian tries to establish the relationship between the existance of illegal business of psicoactive drugs, of various and powerful criminal groups linked to this business and the consequences for the perception of National Security in the Colombian case. Thus, he sets the colombian "strategic dilemma" in a double dimension: an absolute confrontation with the organized narco-crime weakens to the national government, but to elude the fight against drug dealers weakens Colombia in the international sphere.

Key words: Colombia, psicoactive drugs, organized crime, national security, illegal business of psicoactive drugs.

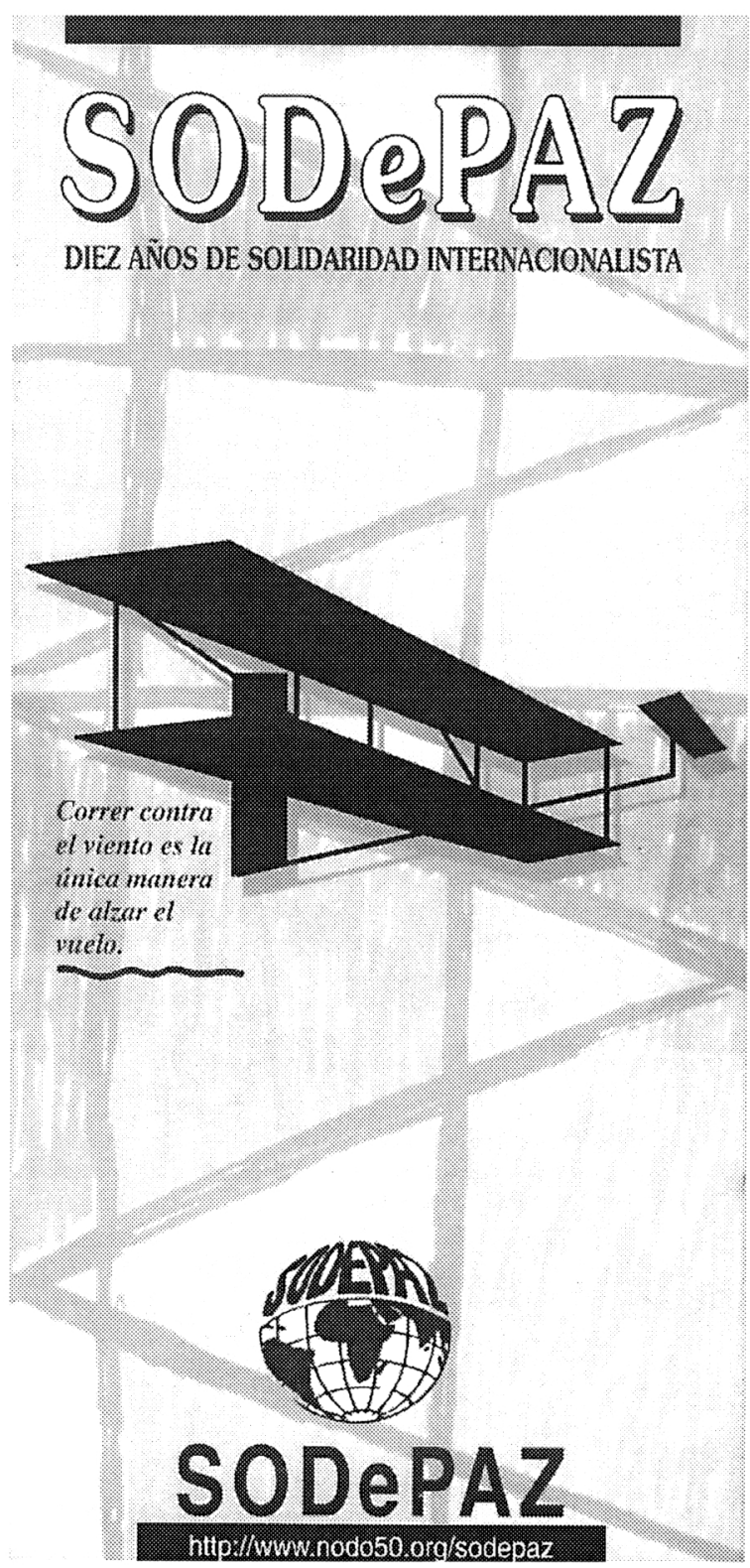

